\title{
AS CRIANÇAS SURDAS E A PALAVRA ESCRITA*
}

Rosane Aparecida Favoreto da Silva

\section{Introdução}

O ser, essencialmente, ser de linguagem.

O ser, sobretudo, seres na linguagem.

O dar a linguagem.

$O$ dar a ver a linguagem.

O oferecer a linguagem.

Carlos Skliar

Este capítulo tem como pano de fundo os Estudos Surdos e a educação bilíngue de surdos (a Libras como a primeira língua e o Português, na modalidade escrita, como a segunda), tendo em vista as especificidades linguística e sociocultural que fazem parte do jeito surdo de ser. Os Estudos Surdos têm evidenciado a necessidade de múltiplos olhares sobre os surdos e a surdez, destacando a importância de a pessoa surda transitar na sua própria cultura e compartilhar os artefatos e elementos que a compõe com outros surdos. Müller e Karnopp (2015, s/p) ressaltam que "[...] é o entendimento que se tem sobre a surdez e o ser surdo, sobre a sua educação e cultura, que vai mobilizar as lutas, conduzir o trabalho dos profissionais, aprovar políticas, direcionar ou não recursos para efetivar uma educação escolar bilíngue, entre outros movimentos".

Fundamentado nesses pressupostos, este capítulo foi elaborado a partir dos resultados de uma investigação (FAVORETO DA SILVA, 2020), que teve como objeto a apropriação da língua portuguesa escrita pelas crianças surdas, sinalizantes de Libras. Mesmo que as práticas docentes influam na aprendizagem, este estudo não visou às questões relacionadas ao ensino, mas sim como as crianças surdas, no início da escolarização, aprendem a língua escrita.

*DOI - 10.29388/978-65-86678-60-4-0-f.301-328 
Vygotsky (1984) e Luria (1988) estão entre os autores que se interessaram pelo percurso da criança ouvinte durante o seu processo de desenvolvimento da escrita, e suas obras contribuíram com a fundamentação deste estudo. Suas pesquisas têm similaridades com aquelas realizadas por Ferreiro e Teberosky (1999), sobre a psicogênese da escrita, que investigaram a aprendizagem inicial da língua escrita pelas crianças; entretanto, diferenciando-se em relação ao objeto de conhecimento. Em suas obras, esses autores apontaram que as crianças formulam hipóteses, fazem conjecturas sobre a escrita e são criadoras dos instrumentos de seu conhecimento; entretanto, esse processo não acontece somente com as crianças ouvintes. No caso das crianças surdas o que difere é que o desenvolvimento da escrita não está relacionado com a rota auditiva.

Os colaboradores da pesquisa foram seis crianças surdas, com idades entre três e doze anos, que cursavam a Educação Infantil e os anos iniciais do Ensino Fundamental em uma escola de surdos localizada no Estado do Paraná. O método adotado para a obtenção dos dados escritos e verbais/discursivos foi o de entrevista semiestruturada, juntamente com um conjunto de procedimentos apresentados mais adiante. Considerando que o uso de instrumentos como as histórias infantis aproxima o pesquisador e a criança, podendo envolvê-la por meio de propostas lúdicas, foi desenvolvido um roteiro de atividades partindo da contação de uma história infantil em Libras, adaptação do livro Viviana, a Rainha do Pijama, de autoria de Steve Webb. Nas atividades apresentadas neste texto as crianças: a) escreveram os seus nomes; b) fizeram atividades com a escrita de vocabulário envolvendo os nomes dos animais que são personagens do livro e, também, de outros que foram escolhidos por elas e inseridos no roteiro; c) e, escreveram uma carta resposta à menina Viviana, como produção textual do gênero carta.

As entrevistas foram realizadas em língua de sinais e, além do assentimento das crianças (KRAMER, 2002), a participação de cada uma foi autorizada por meio do Termo de Consentimento Livre e Esclarecido (TCLE) pelos seus respectivos responsáveis legais, cumprindo todos os requisitos das determinações que normatizam a ética na pesquisa com seres humanos, de acordo com o parecer da Comissão de Ética da FEUSP № 082/2017.

A seguir estão dispostos os resultados obtidos e as discussões dos dados da pesquisa. Os resultados serão apresentados em ordem cronológica de idade dos colaboradores; entretanto, essa forma de organização não 
significa uma linearidade no desenvolvimento da escrita das crianças. Neste texto, os colaboradores serão identificados com as iniciais de seus nomes seguidos das respectivas idades: JO03, PE05, AD08, JV09, MAR11, JA12.

\section{As experiências e as palavras}

\section{Criança JO03: O desenho e a palavra}

$\mathrm{Na}$ entrevista com o colaborador $\mathrm{JO03}$, entre os aspectos que se destacaram está a forma pictográfica de registro. A criança se comunicava e interagia por meio Libras e estava em fase de aquisição da linguagem no período de realização das entrevistas. Em relação ao processo de apropriação da escrita, verificou-se que $\mathrm{JO03}$ estava em fase de transição de uma técnica de escrita para outra; ou seja, a criança utilizou os desenhos para realizar seus registros, mas também fez uso de letras em alguns momentos, na direção da apropriação da escrita alfabética convencional. De acordo Luria (1988, p. 180), "como qualquer outra função psicológica cultural, o desenvolvimento da escrita depende, em considerável extensão, das técnicas de escrita usadas e equivale essencialmente à substituição de uma técnica por outra"; pois, é no uso de cada técnica que o desenvolvimento da escrita se aprimora gradualmente. Esse processo não acontece de forma linear, com crescimento e aperfeiçoamento contínuos. $\mathrm{JO03}$ fazia o uso de desenhos como representação da escrita, mas também conhecia algumas letras e números; já havia tido contato com a escrita por meio da mediação do professor, pois iniciara o seu processo de escolarização no ano da entrevista.

Quando perguntado pelo seu nome, a criança sinalizou J-O-E-S-A usando a datilologia e, em seguida, fez o seu sinal. Registrou o seu nome no papel começando da direita para a esquerda, sem seguir as convenções da escrita - OOÃJ (colocou o til embaixo da A) -. Escreveu o nome no papel de forma diferente daquela como fez na datilologia, usando todas as letras que compõem o seu nome; mas em ordem diferente de como deveria ser a escrita. Após, sem que fosse solicitado, desenhou a si próprio ao lado do nome e a sua mão fazendo o número quatro, o qual disse indicar a sua idade. J003 tinha três anos, mas dizia ter quatro tendo em vista que a data de seu aniversário se aproximava. 
Imagem 01: Registro do nome por JO03

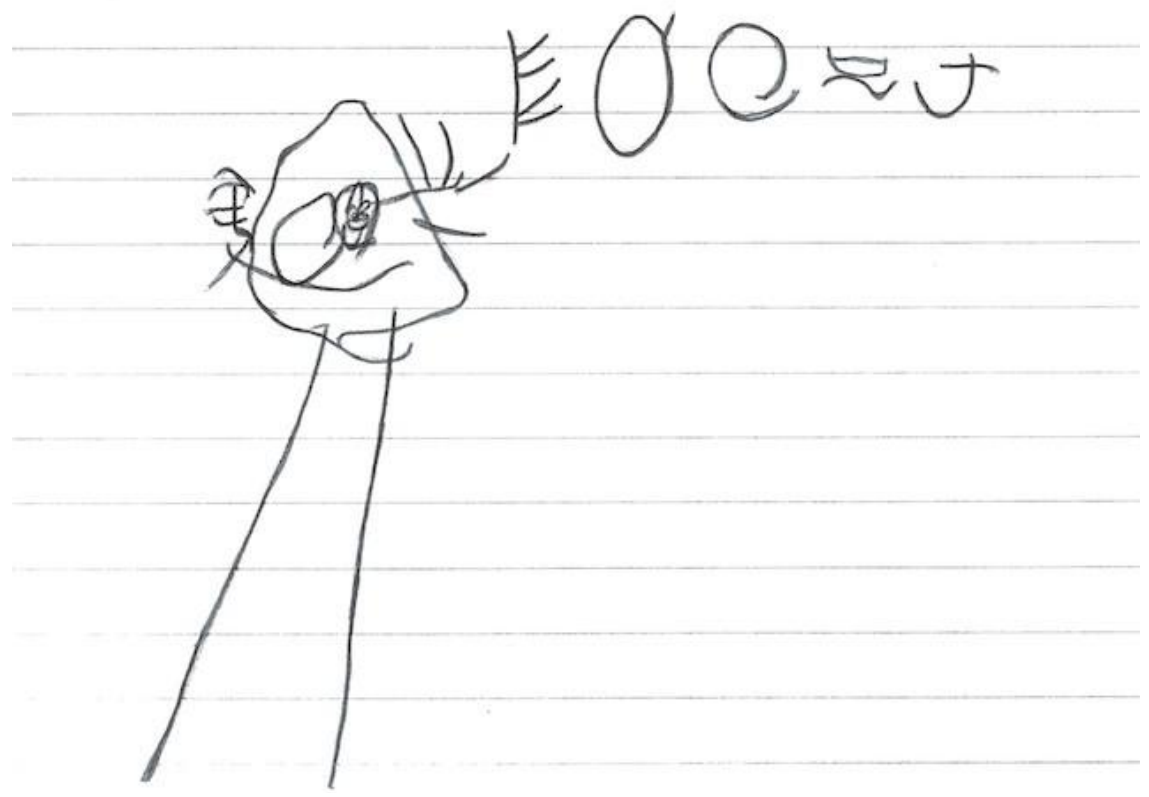

Fonte: Favoreto da Silva (2020)

Nas atividades com vocabulário, $\mathrm{JO03}$ registrou os nomes dos animais contornando os respectivos bonecos com o lápis, desenhando-os e fazendo os olhos e bocas à mão livre. $\mathrm{JO03}$ recorreu à forma de registro pictográfico pelo fato de não saber como poderia registrar os nomes dos animais com o uso das letras, por meio da escrita simbólica convencional, e o desenho infantil passou a ser significativo pelo ato de nomear (ZERBATO; LACERDA, 2015). Para Luria (1988, p. 176), uma criança pode desenhar bem, mas este desenho pode não ter a função de um recurso auxiliar para ela; e, "isto distingue a escrita do desenho e estabelece um limite ao pleno desenvolvimento da capacidade de ler e escrever pictograficamente, no sentido mais estrito da palavra". Portanto, quando a criança utiliza intencionalmente o desenho para compreender o uso instrumental de uma imagem como um símbolo, como um referente auxiliar da memória, ela passa a se aproximar do uso da escrita simbólica convencional. A diferença não está na forma do grafismo, mas na sua 
funcionalidade, sendo que o desenho pode ser utilizado tanto como desenho autocontido, com valor em si mesmo, quanto como escrita pictográfica, conforme afirma a Azenha (1995) em sua obra sobre o grafismo infantil.

Os desenhos infantis fazem parte de uma rica experiência da fase pictográfica do desenvolvimento da escrita, de acordo com Luria (1988). No início, esses registros podem se caracterizar apenas como uma brincadeira, sem a função de signo mediador no processo intelectual, para posteriormente, ser empregado como um meio para registro. Neste período, a criança compreende que o objeto pode ser substituído por alguma parte dele ou por seus contornos, cuja fase de aquisição de habilidades psicológicas se efetiva como a base para o desenvolvimento da escrita simbólica.

$\mathrm{Na}$ transição entre a escrita pictográfica e a convencional, conforme a criança aprimora a sua escrita pictográfica, ela apropria-se de letras e números, passando a utilizar essas representações nas suas produções e podendo fazer combinações da escrita pictográfica com a escrita simbólica convencional. A transição entre essas fases pode ser observada nas produções subsequentes de $\mathrm{JOO3.}$

Em uma atividade em que foi solicitado a escrever a palavra "vaca", animal escolhido pelo JO03, ele não utilizou o desenho, pois já havia uma imagem da vaca e ao seu lado uma linha para a escrita do nome do animal. Ao escrever o nome da vaca seguiu as convenções da escrita, escrevendo da esquerda para a direita, registrando JOOA67. A criança utilizou as letras de seu nome, mas em uma ordenação diferente de quando escreveu o seu nome, e acrescentou alguns números; porém, escreveu as letras J e A de ponta cabeça e os números seis e sete espelhados, ao contrário. Um detalhe a se destacar é que $\mathrm{JO03}$ usou números ao final da palavra, ele não os colocou entre as letras; de certa forma, houve uma separação das letras e dos números. De acordo com Ferreiro e Teberosky (1999) é comum que crianças confundam as letras e números quando escrevem, não só pelas semelhanças gráficas, mas principalmente pelo desenho representativo da escrita, tendo em vista que se escrevem os números, assim como as letras, e ambos estão empregados em vários contextos similares. Para essas autoras, um problema real é que o número possa ser lido, apesar de não ter letras, ressaltando que esse problema se resolve quando a criança toma consciência de que números estão escritos em um sistema de escrita diferente ao do sistema alfabético, utilizado para escrever palavras. Também evidenciam que é comum encontrar a 
denominação "números" aplicados às letras nos registros das crianças, mas nunca a denominação "letras" aplicada a números. Esta forma de registrar, utilizando números e letras para compor uma palavra não é um indicador de confusão conceitual pela criança (FERREIRO; TEBEROSKY, 1999).

Na produção do texto do gênero carta $\mathrm{JO03}$ não usou letras. O texto que foi solicitado a escrever era uma carta resposta da personagem vaca destinada à menina Viviana. O colaborador colocou o boneco da vaca no papel e contornou com o lápis, desenhando-o, assim como fez quando registrou os nomes dos animais personagens do livro; ou seja, a criança utilizou a mesma estratégia para registrar um texto e para registrar o vocabulário, não diferenciando um do outro. Entretanto, não utilizou a mesma forma de registro na carta convite e na carta resposta, usando letras e números na primeira e desenho para registrar a segunda. Essas formas de registros empregadas por $\mathrm{JO03}$ evidenciam a transição de uma técnica para outra; porém, as letras ainda não são utilizadas como símbolos, mas como uma representação externa e como cópia desprovida de significado.

\section{Criança PE05: As letras do nome e a interação com o vídeo}

Na entrevista com o colaborador PE05 dois pontos se destacaram: a forma de registro das palavras, usando as letras de seu nome; e, também as suas tentativas de interação com a contadora da história, em Libras, por meio do vídeo.

A criança se comunicava e interagia por meio da Libras, todavia a sua aquisição da língua de sinais teve início no ambiente escolar no ano em que a entrevista foi realizada. Quando perguntado qual era o seu nome, a criança usou a datilologia e escreveu-o no papel corretamente. Na realização das atividades com vocabulário, ao buscar escrever os nomes dos personagens do livro PE05 utilizou as letras que compõem seu nome, acrescentando algumas vogais em determinadas palavras.

Ao registrar os nomes dos animais, PE05 escreveu no papel PEREPDOR para a palavra "leão"; e, quando foi perguntado o que estava escrito, ele sinalizou P-E-D-R-O, usando a alfabeto manual. Em seguida, disse que não era essa a palavra e sinalizou P-E-D-R-E-P-R-D-O-R, usando a datilologia. PE05 disse que no papel estava escrito a palavra "leão". 
Escreveu: RORROE para macaco; DREDDO para girafa; RDERPE para jacaré; RDEAP para polvo, utilizando uma vogal diferente daquelas que compõem o seu nome - a letra ' $A$ '- , e ao fazê-lo mostrou à pesquisadora; PEADAR para urso, continuando a inserir a letra ' $A$ '; RDDER para pinguim; e, por último, RADRI para a palavra menina, utilizando também a letra ' $I$ ', novamente avisando a pesquisadora sobre essa ação.

Imagem 02: Registros de PEO5 utilizando as letras de seu nome.

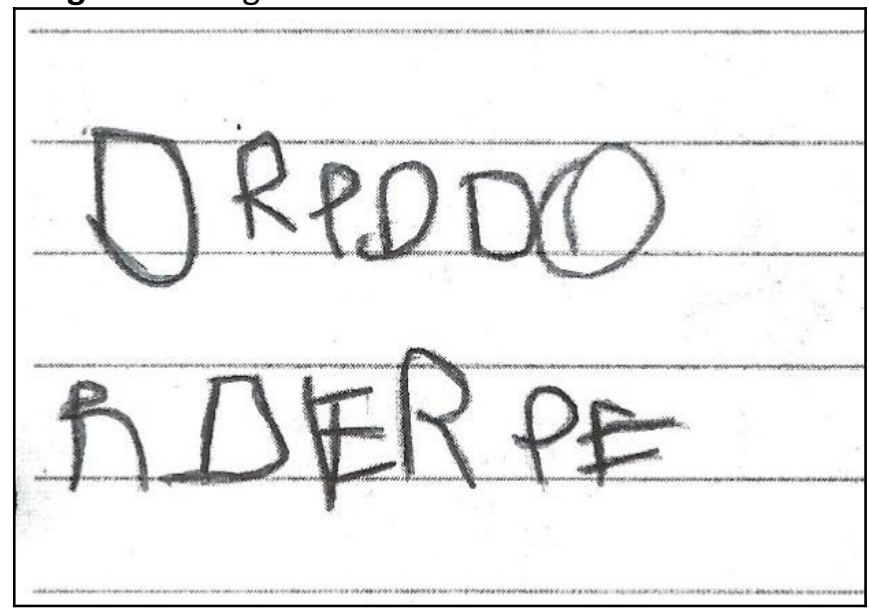

Fonte: Favoreto da Silva (2020)

Na ocasião, constatou-se que PE05 conhecia as letras isoladamente, sabia suas formas e como escrevê-las no papel, não as inventando; ele compreendia que as letras podiam registrar conteúdos, mas ainda não compreendia como funcionava o sistema de notação da escrita alfabética. 0 colaborador utilizou as letras que compõem o seu nome, que é uma palavra estável, para escrever as palavras solicitadas, não repetindo a mesma sequência de letras. Ou seja, a criança compreendia que para escrever coisas diferentes, era necessária a diferenciação entre a escrita de uma palavra e da outra. Tais características também foram observadas pelas pesquisadoras Ferreiro e Teberosky (1999) nas pesquisas sobre a psicogênese da língua escrita, realizadas com crianças ouvintes. Em sua tese de doutorado sobre a psicogênese da escrita em crianças surdas, Machado (2000) constatou formas de escrita semelhantes à de PE05 em duas produções, onde as crianças 
registravam mudando a ordem das letras e com variedade interna, buscando garantir os significados diferentes das palavras.

O total de letras utilizado pela criança nas suas produções não tem correspondência com as partes da palavra (as suas sílabas), pois não faz relação com a pauta sonora, tendo em vista a ausência (total ou parcial) da rota auditiva nas pessoas surdas. Portanto, não havendo a correspondência sistemática que constitui a hipótese silábica - Ferreiro e Teberosky (1999) - nas produções escritas de PE05.

$\mathrm{Na}$ escrita do vocabulário PE05 escreveu as letras com caixa alta e registrou as suas formas corretamente; porém, na produção do texto do gênero carta a criança escreveu de modo contínuo, remetendo à escrita em letra cursiva, produzindo a carta por meio de rabiscos e desenhos que lembram letras, de forma imitativa e externa, buscando reproduzir a escrita em sua forma externa, sem compreender o seu significado funcional, conforme se evidenciou na pesquisa de Luria (1988) com crianças ouvintes. Verificou-se que a criança compreendia que a escrita de um texto é mais longa do que a de uma palavra apenas, havendo a necessidade da utilização de uma quantidade maior de letras e, consequentemente, sendo de um 'tamanho' maior, o qual ocupa grande parte da folha de papel.

\section{Criança AD08: A imaginação e a palavra escrita}

Os pontos que se destacaram na entrevista com o colaborador AD08 são: a sua intensa comunicação e imaginação para relatar histórias. A criança se comunicava e interagia por meio da Libras e a compreensão dos conceitos Ihe possibilita um conhecimento do mundo e das coisas que o rodeiam, favorecendo que ele formulasse perguntas e contasse coisas relacionadas às suas experiências, como os questionamentos sobre o que via no livro de história utilizado nesta pesquisa.

Quando perguntado qual era o seu nome e sinal, respondeu usando a datilologia com destreza e desenvoltura. Na realização das atividades com vocabulário, AD08 comentou sobre cada animal personagem do livro, levantando hipóteses sobre eles e criando histórias, relacionando-os ao seu dia a dia, como fez ao contar as pernas do polvo e compará-las com o total da sua idade. 
Ao ser solicitado que escrevesse, disse que conseguia fazê-lo e realizou algumas estratégias para não efetuar essa ação. Ao sinalizar que sabia escrever o nome do leão, ficou pensativo, fez a letra " $E$ " usando a datilologia e buscou o consentimento da pesquisadora; em seguida, fez a letra " $L$ ", também por meio da datilologia, escreveu a letra e permaneceu pensativo. AD08 escreveu a palavra ELA para "leão" e não quis escrever o nome dos outros a animais. Cabe ressaltar que a palavra "ela" contém as letras que compõem a palavra "leão".

Usando o livro da história infantil o AD08 encontrou rapidamente a palavra "leão" por meio das pistas visuais, escrevendo-a corretamente, copiando-a; assim como fez com a palavra "girafa" e com o nome da menina "Viviana". Tal fato evidencia a importância da visualidade no aprendizado da escrita pelas crianças surdas, tendo em vista que não fazem uso da consciência fonológica neste processo; e, portanto, não fazendo a relação da escrita com a pauta sonora como uma habilidade metalinguística para o aprendizado da escrita. Ou seja, no caso das crianças surdas, a escrita não se caracteriza como a fala tornada visível, conforme apontado por Soares (2016) referindo-se às crianças ouvintes. Tendo em vista os conhecimentos que AD08 possui, destaca-se a necessidade de mediações efetivas de um adulto para que a criança passe a compreender o sistema de escrita alfabético.

Imagem 03: Registros de AD05

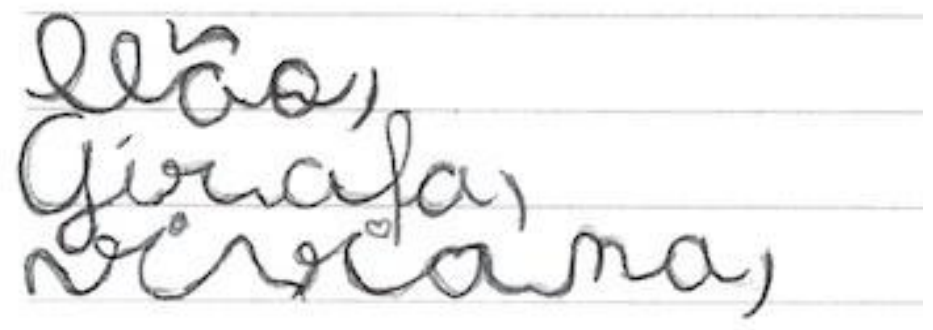

Fonte: Favoreto da Silva (2020)

Nas atividades anteriores, AD08 havia encontrado e copiado as palavras; mas, ao registrar o lugar em que o animal morava escreveu a palavra CASAS, diferentemente da forma como tinha ocorrido, constatando outra atividade mental na criança: percebeu-se que ficou pensativo, olhando para 
um lugar indefinido, recorrendo à memória para poder escrever. AD08 fez datilologia para si, assim como uma criança ouvinte pronunciaria para si as letras que pretende escrever quando está pensando sobre elas. Inicialmente, sinalizou por meio da datilologia C-S e em seguida A-S, sempre pensativo, escreve, apaga e retoma a datilologia $C-A$, questiona se realmente é o $A$; e, por último sinaliza as seguintes letras para si A-C-A-S-A, coloca a mão no rosto, tentando se lembrar como escreve e continua fazendo datilologia, A-S.

Para Gesueli (1998), as crianças surdas trazem os conhecimentos linguísticos que possuem para a realização das atividades de escrita, sinalizando para si e depois realizam o registro da palavra, assim como os ouvintes tentam escrever a partir de sua fala. O fato de a criança fazer datilologia para si própria também pode se caracterizar como uma fala egocêntrica, tendo em vista que a relação entre o pensamento e a palavra é um processo, um movimento contínuo, de duas vias, do pensamento para a palavra e vice-versa (VYGOSTY, 2001). Neste sentido, a criança recorre à fala egocêntrica, como uma função ligada ao pensamento, sendo utilizada na solução de problemas como um instrumento intrapsíquico, ou seja, individual.

Ao iniciar a escrita do texto da carta, a criança permaneceu hesitante e logo começou a escrever, continuando a fazer datilologia de algumas letras para si e os seus registros. AD08 escreveu várias letras juntas, sem separação, em duas linhas da folha, como se fosse uma só palavra em cada linha. Apesar de sua escrita não ter sentido, escreveu com letra cursiva e na sua escrita se evidenciou que ele conhecia algumas propriedades do sistema de escrita alfabética (MORAIS, 2012), demonstrando quando faz a junção consoante e vogal e/ou consoante, consoante e vogal. Constatou-se que a criança considerava que um texto é algo escrito com muitas letras, por isso as escrevia seguidamente, sem espaçamento.

Ao ser perguntado o que escrevera, AD08 sinalizou que na primeira linha estava escrito o nome de vários animais e na segunda era sobre suas roupas. Foi solicitado que ele escrevesse o nome do tigre, assinando a carta, pois queria ver como o colaborador escreveria esta palavra; o colaborador fez datilologia usando a letra S e escreveu LEÃO. Quando perguntado o que escrevera disse: "tigre, animais vários, resposta com vários nomes".

Nesta entrevista, evidenciou-se que ao mesmo tempo que AD08 tinha conhecimento das coisas que o rodeavam e interagia ricamente em língua de sinais, ele apresentou resistência para escrever, talvez por ter dúvidas sobre 
como registrar a palavras, havendo a hipótese de que a criança tenha consciência que a escrita denota o objeto, mas ainda não entendeu como funciona o mecanismo do sistema da escrita alfabética. Machado (2000, p. 177), afirma em sua tese que "[...] essas crianças compreenderam "como" a escrita representa sem a compreensão "do que representa", cujos dados mostram que a escrita possui características que revelam a sua natureza "alfabética", independe de sua fonetização".

Desta forma, AD08 transitou entre copiar e tentar escrever, a partir de sua recorrência à memória. A cópia exige um esforço menor do que escrever partindo de suas ideias, ocasionando que a criança recorra a essa ação. AD08 agia de forma perspicaz e fazia os registros com uma letra bonita, podendo cumprir os rituais de sala de aula (GOES; TARTUCI, 2014), fazendo cópias ao incorporar artifícios que "simulam" a vivência do processo de letramento, com pouca aprendizagem efetiva de como se escreve as palavras e um texto.

\section{Criança JV09: As palavras, os desenhos e as marcas escolares}

$\mathrm{Na}$ entrevista com o colaborador JV09 os pontos que se destacaram foram: o uso de desenhos para complementar a escrita convencional e as marcas de suas experiências escolares, principalmente no que se refere às suas produções escritas, como também na aquisição da linguagem.

JV09 se comunicava e interagia por meio da Libras, mas não era fluente nesta língua quando foi entrevistado; entretanto, estava em processo de aquisição da língua de sinais, diante das interações e as práticas vivenciadas na escola em que estudava no período da pesquisa. Há a hipótese de que as experiências escolares anteriores ocorreram a partir de referenciais audiológicos e da deficiência, interferindo na aprendizagem dos conteúdos escolares como, também, na sua aquisição da linguagem. Segundo Karnopp e Lopes (2014) se a normalidade for definida por esses referentes, a surdez passa a ser concebida como uma deficiência que incapacita e fragiliza as pessoas surdas independentemente do tipo de escola que frequentam, diante de que a aprendizagem escolar decorre das experiências vividas neste espaço; desta forma, é fundamental pensar a pessoa surda a partir de um contexto em que a surdez não é um limitador, mas um traço que pode estar associado às experiências visuais e a uma gama de práticas linguístico-culturais fundamentais para o desenvolvimento. 
No início da entrevista, quando perguntado qual era o seu nome, JV09 usou a datilologia para dizê-lo, depois fez o seu sinal e o da série em que estudava. Seguiu as convenções, escrevendo-o corretamente e com letra cursiva.

Na realização das atividades com vocabulário, quando JV09 registrou o nome do pinguim, verificou-se um comportamento diferenciado e uma possível atividade mental de recorrência ao que tem sido denominado de fala egocêntrica (VYGOSTKY, 2001); pois, inicialmente, ele fez datilologia para si, sinalizando as letras S-M-O e, posteriormente, L-E-L-E. O mesmo processo se efetivou quando escreveu o nome do jacaré; sendo que fez datilologia usando as letras U-E-L-J-O-I, não as escrevendo, aguardando o consentimento da pesquisadora. Foi solicitado que escrevesse e, então, recorreu à memória, fazendo datilologia para si usando as letras L-J-C e depois A-I, sinalizando com uma mão e escrevendo com a outra.

Na escrita dos nomes da girafa, do polvo, do macaco e do urso, JV09 não recorreu à datilologia como um recurso de instrumento para a memória; ele escreveu as palavras sem hesitar. Após, buscou-se verificar se a criança fazia correspondência do registro com o respectivo animal, constatando-se que a escrita ainda não se caracterizava como um recurso auxiliar para se lembrar do conceito que registrou.

Desta forma, foi solicitado que JV09 escrevesse novamente o nome do macaco, sendo que escreveu uma palavra diferente daquela que escrevera inicialmente; na primeira tentativa, escreveu INAZXIK e na segunda WZIKM. A forma como foi realizada a escrita revela que a criança ainda não havia compreendido o mecanismo da escrita simbólica, ou seja, ainda não tinha compreendido como as letras notam, empregando-as externamente e de forma imitativa, pensando que estas marcas em si poderiam ajudá-lo (LURIA, 1988). As produções de escritas foram realizadas em caixa alta, com exceção de seu nome, usando uma ordem diferente das letras para cada palavra, as letras não notavam uma palavra corretamente, pois não havia compreendido o funcionamento do sistema de escrita alfabética. Quando indagado quais eram os nomes escritos JV09 respondeu seguindo a ordenação em que os animais estavam dispostos na mesa.

$\mathrm{Na}$ atividade de escrita de vocabulário com nomes de animais JV09 usou as letras para registro, mas para a realização do texto no envelope e na carta resposta recorreu a letras e desenhos. No momento da produção do 
texto do gênero carta, a criança pegou a carta do boneco do pinguim para copiá-la e foi dito a ela deveria escrever uma carta resposta diferente, não poderia copiar. Entretanto, copiou o início da carta onde estava escrito "Cara Viviana", escrevendo "Cara Vivina", seguido dos registros das palavras ONLHKOLI, NEMIQPG e MSZIAXX (letra S invertida) e, ao lado, desenhou um bolo com velinhas e uma casa. Quando perguntado o que escrevera, JV09 respondeu que era "escova de dente" (remetendo ao jacaré) e depois fez o sinal de "escrever"; ao ser indagado o que havia escrito, JV09 sinalizou: "rato" e, posteriormente, "parabéns", "comer" e "casa", referindo-se à festa de aniversário para a qual o rato fora convidado. Neste caso, o desenho foi utilizado como um mediador da memória e não como uma representação em si mesmo.

Imagem 04: Registros de JV09 realizados no envelope da carta

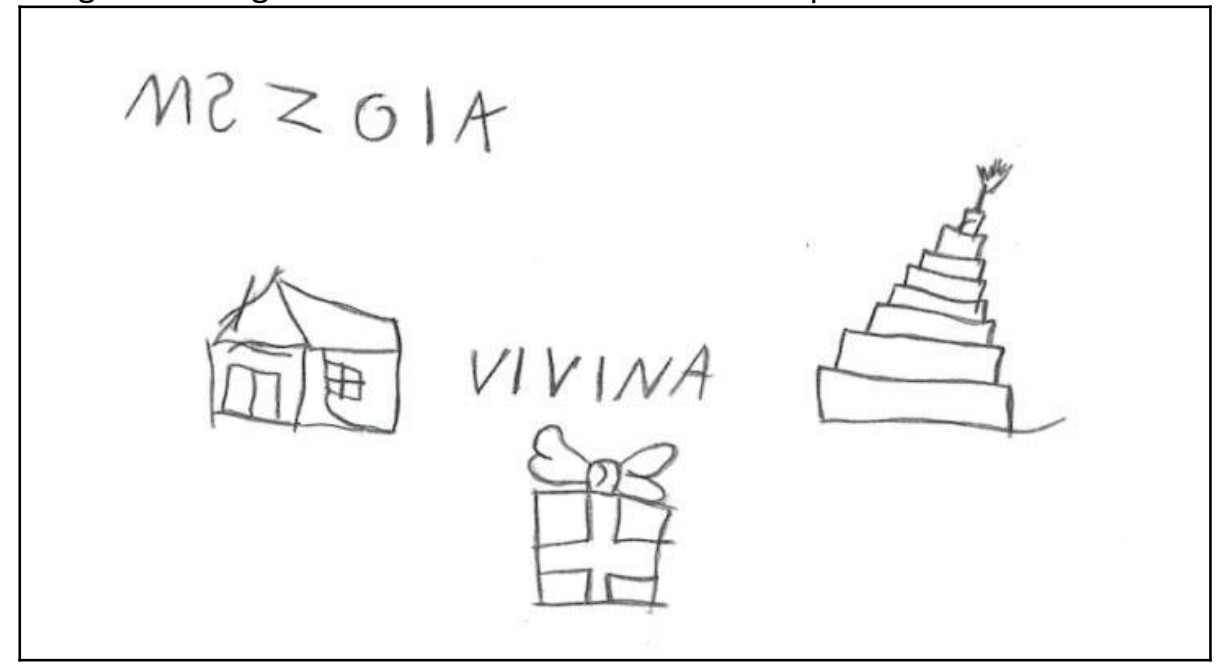

Fonte: Favoreto da Silva (2020)

Diante dos resultados apresentados nos textos, é possível dizer que JV09 estava em fase de transição entre o registro pictográfico e a escrita com signos simbólicos convencionais. A criança conhecia as formas das letras, usando-as para escrever; porém, empregou-as de forma isoladas para registrar os conteúdos, ainda não tendo compreensão do sistema de escrita alfabético e nem conhecendo as suas propriedades (Morais, 2012); por exemplo, não utilizou a junção consoante-vogal ou consoante-consoante-vogal, entre outras, 
para registrar as palavras, usando as letras de forma imitativa e aleatória. Para Azenha (1995) a habilidade em escrever letras não implica que a criança tenha uma compreensão que possibilite demonstrar um comportamento diferenciado em relação à escrita, fazendo distinções específicas entre as grafias no registro de conteúdos diferentes.

Silva (2008) constatou em sua pesquisa com crianças surdas que na fase pictográfica e na de transição, respectivamente, a criança busca combinar a escrita pictográfica com fragmentos da escrita convencional, contudo prioriza o uso dos símbolos da escrita convencional, tendo em vista que pelo fato de não dominar o sistema de escrita alfabético, emprega as formas pictográficas para realizar os seus registros, conforme também verificado nas produções de JV09.

Nas produções de textuais, como no texto da carta resposta, além de letras, JV09 usou desenhos com uma função complementar à escrita. Azenha (1995, p. 171) em sua pesquisa constatou situação semelhante com crianças ouvintes, em que os desenhos parecem registrar algo de que se fala a respeito de uma referência presente na escrita ou, inversamente, marcam o objeto representado do qual a escrita se refere; pois, neste caso, "desenho e escrita parecem ocupar lugares complementares na produção gráfica, e a imagem não aparece paralela à escrita apenas para garantir a evocação dos significados às quais se refere". Neste contexto, conforme autora em questão, desenho e escrita estão relacionados um ao outro e não são redundantes, sendo que o registro pictográfico pode se constituir como o próprio desenho da sinalização da criança, desempenhando uma função de apoio como recurso auxiliar à memória; e, essa descoberta de que se pode registrar a fala por meio de desenhos pode levar a criança à escrita convencional, conforme já ressaltado nos comentários sobre a entrevista do colaborador JO03. Conforme Vygotsky (1984) foi a descoberta de que se pode "desenhar" a fala que levou a humanidade ao brilhante método da escrita por letras e frases.

A partir da premissa que o desenho se constitui como uma das formas de elaboração das funções mentais superiores e que é marcado pela construção da língua, na pesquisa que compõe o artigo de Zerbato e Lacerda (2015) foi verificado que intervenções usando diferentes tipos de linguagem se mostraram efetivas para a construção e desenvolvimento das crianças surdas, evidenciando a importância da língua de sinais e da atividade do desenho como recurso sígnico, tendo em vista que o desenvolvimento da língua de 
sinais está diretamente relacionado com o desenvolvimento das atividades simbólicas e a mediação do outro na construção do conhecimento.

JV09 mostrou-se uma criança esperta e curiosa em relação às coisas que o rodeiam; assim, cabe ressaltar suas possibilidades de aprendizagem e lembrar que, de acordo com Luria (1988, p. 144), a escrita é uma função que se realiza, culturalmente, por mediação. Portanto, de acordo com Vygotsky (1984, p. 120) cabe à escola o ensino da linguagem escrita - "[...] como um sistema particular de símbolos e signos cuja dominação prenuncia um ponto crítico em todo o desenvolvimento cultural da criança" -, e não apenas a escrita de letras como uma habilidade motora e mecânica.

\section{Criança MAR11: As palavras escritas e a Libras}

Entre os pontos que se destacaram na entrevista da colaboradora MAR11 estão as pistas visuais e as marcas da Libras nos seus registros. A criança se comunicava fluentemente e interagia por meio da Libras, tendo adquirido essa fluência nas práticas vivenciadas na escola em que estuda. No início da entrevista, quando perguntado qual era o seu nome, MAR11 respondeu usando a datilologia e, em seguida, fez o seu sinal, escrevendo o seu nome com uma letra cursiva bem definida e caprichada.

No momento da escrita dos nomes dos animais, ao buscar escrever a palavra leão MAR11 sinalizou L-E usando a datilologia e, após, aguardou o consentimento para continuar a ação, escrevendo LEIO para o nome do animal. Em seguida, escreveu o nome do pinguim, registrando BEIJO; para jacaré escreveu JOUOVOPO; para girafa registrou AFIO; para polvo escreveu JORENZO; para macaco, MACOCOCA e para urso, UREO. Em seguida buscou-se verificar se a criança conseguia identificar os nomes que tinha escrito, usando os registros como um recurso para a memória. MAR11 conhecia as letras e propriedades do sistema de escrita alfabético, usando as combinações consoante-vogal, consoante-consoante-vogal, consoante-vogal-vogal, entre outras; escreveu algumas palavras que conhecia, conseguindo identificá-las, relacionando-as aos conceitos que utilizou. Entretanto, nesta atividade, um ponto que se destacou foi a importância da visualidade no processo de apropriação da escrita; pois, há a hipótese de que MAR11 tenha feito tais escolhas para escrever os vocabulários diante de sua relação visual com as palavras que os representam. Por exemplo, ao escrever LEIO, MAR11 utilizou 
as letras LE de leão, mas, na dúvida, escreveu LEIO que é uma palavra que ela conhece; ao utilizar a letra J para iniciar a palavra jacaré, pode-se dizer que foi uma estratégia relacionada à visualidade e não à questão da relação com o som da letra. Em pesquisas realizadas com crianças surdas sobre a escrita, Pereira (2015) observou situação semelhante a essa, constatando o registro de algumas pseudo-palavras, mas que traziam fragmentos da forma convencional da escrita; por exemplo para "Terezinha", foi escrito "Tecamca".

Pereira e Rocco (2009) e Pereira (2015), constataram também que, quando a criança tem dúvidas sobre como escrever, utiliza palavras que já conhece e que são familiares para ela, mesmo que não façam parte do contexto da atividade, que é o caso das palavras "leio" e "beijo", registradas pela colaboradora. Em sua tese sobre a escrita de pessoas surdas, Oliveira (2009) propõe o conceito de consciência visual para interpretar esse mecanismo de registro da escrita que reflete na representação do objeto via expressão gráfica, como: a visualização do objeto pelo contato direto ou experiência concreta; a representação de um traçado gráfico apoiada pela memorização; representação de um objeto sustentada a partir de uma referência, como a língua de sinais. De toda forma, evidencia-se os processos que envolvem a visualidade no desenvolvimento da escrita de crianças surdas. Em outra atividade de vocabulário, com animais inseridos no roteiro, MAR11 teve a opção de escolher quais nomes registraria, escrevendo-os corretamente e usando o gênero feminino para a maioria dos registros: ELEFANTA, RATA, SAPA e GATO.

$\mathrm{Na}$ atividade de produção do texto do gênero carta quando perguntada sobre o que havia escrito, a colaboradora sinalizou, lendo a carta em Libras, "A menina foi você festa casa foi sim ou não casa foi sim bom junto gata". Ela não sinalizou a expressão "com afeto, Gata", pois essa parte foi escrita depois, sendo copiada de outra carta. Verificou-se, também, que MAR11 conhecia o conceito "festa", sinalizando-o em Libras, porém não se lembrava como escrevia, registrando F-E-E-A. Destaca-se as marcas da Libras na organização e estrutura morfossintática da carta escrita em língua portuguesa, também verificado na pesquisa com crianças surdas realizada por Pereira e Rocco (2009).

Tendo conhecimento que os alunos da escola estavam aprendendo a escrever em escrita de sinais e que alguns a usavam como recurso para a memória, foi perguntado à MAR11 se era melhor escrever carta em português 
ou SignWriting, e ela respondeu que em SignWriting. Quando indagado o motivo, a menina respondeu com firmeza: "porque é melhor a Libras, eu entendo já. É melhor, eu vou conhecendo mais e percebendo as informações"; então, foi solicitado que escrevesse uma cartinha em escrita de sinais e MAR11 prontamente atendeu.

Enquanto escrevia ela fazia os sinais para si, em Libras, e depois inseriu as palavras em português abaixo ou ao lado da escrita em sinais, sendo que para a escrita em sinais da palavra "festa" MAR11 colocou a tradução como "feea". Na pesquisa feita por Lima, Alves e Stumpf (2018) observou-se uma situação semelhante a essa em relação ao uso da SignWritting, pois a criança analisava o sinal escrito e fazia relações com o sinalizado em Libras, tendo como referencial para a escrita a sua própria língua, "ao expor a escrita da Libras produziu-se nela significado, fazendo-a perceber e atestar que aqueles sinais poderiam ser registrados" (Idem, p. 154).

Imagem 05: Carta produzida por MAR11 em escrita de sinais.

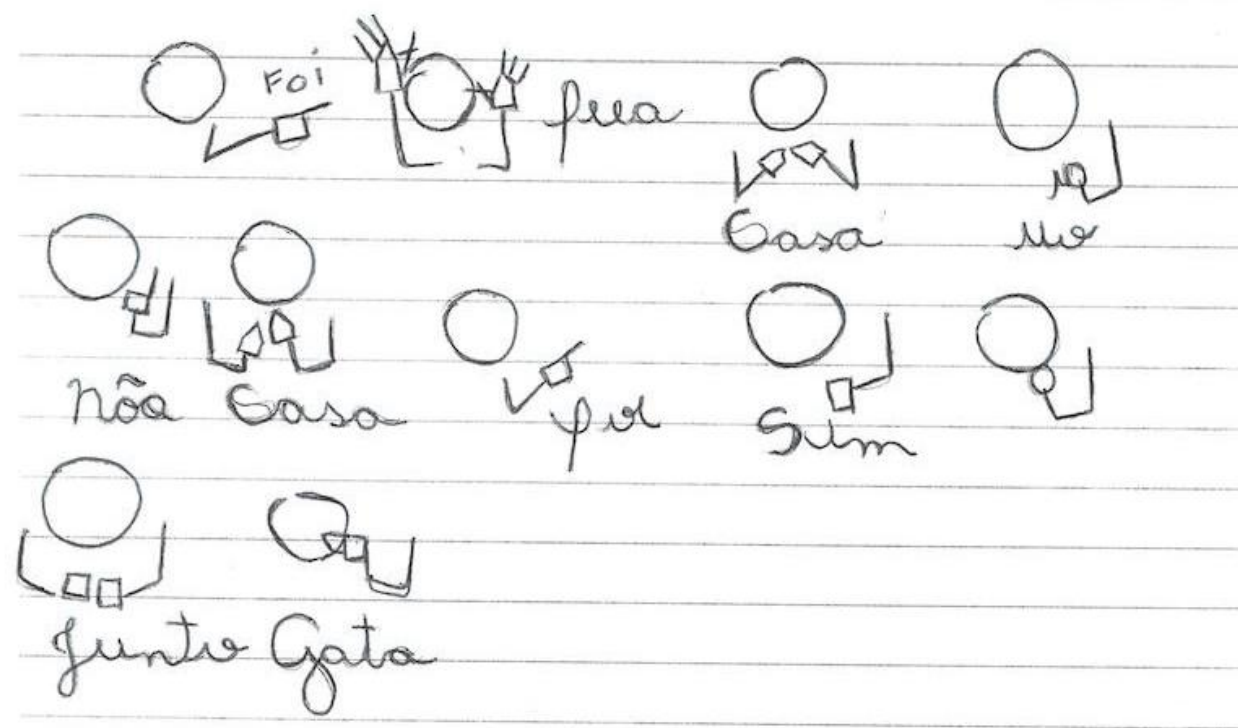

Fonte: Fonte: Favoreto da Silva (2020) 
A criança buscou escrever em sinais o mesmo conteúdo da carta que havia registrado em língua portuguesa, verificando-se que: a) a disposição dos registros pictográficos está de acordo com a estrutura da Libras nas duas cartas; b) a forte influência da língua portuguesa até mesmo quando escreveu em SignWriting. MAR11 escreveu corretamente em escrita de sinais, mas nos seus registros houve a ausência dos símbolos que representam o movimento das mãos e a posição. Ficou claro que a escrita de sinais representa a Libras para esta criança e, também, percebeu-se que ela ficou muito mais à vontade para escrever desta forma do que em português.

Tendo em vista os resultados de sua tese, Silva (2008, p. 207) salienta que "se a escrita é uma forma sofisticada de uso da língua que possibilita ao seu usuário o desenvolvimento de funções psíquicas que dificilmente seriam alcançadas por outra via, é coerente que se empreendam esforços para proporcionar ao surdo o aprendizado da escrita visual direta dos sinais (sign writing) como uma primeira língua escrita". O uso da escrita de sinais não exime as escolas de surdos de ensinarem a língua portuguesa escrita, pois a criança está imersa em uma sociedade grafocêntrica que usa o sistema convencional de escrita. Para Stumpf (2004), as crianças surdas que usam a língua de sinais e que estão em processo de alfabetização em português tendem a representar graficamente a Libras, pois estão aprendendo a língua portuguesa escrita, mas representam também a língua de sinais de uma forma espontânea. Cabe ressaltar, que o uso dessa escrita deve partir da necessidade de um grupo e não de uma imposição acadêmica.

Diante dos resultados desta entrevista, é possível dizer que MAR11 utiliza a escrita de forma instrumental como apoio às funções intelectuais (LURIA, 1988), sendo esse o "ponto de virada" e o requisito fundamental para o uso do sistema convencional de escrita. Para Ferreiro e Teberosky (1999), esse "ponto de virada" se caracteriza quando a criança faz a relação do som e grafema, utilizando a consciência fonológica, o que não é pertinente para as pessoas surdas, diante do seu impedimento auditivo. Silva (2008) ressalta que a criança surda superará a condição abstrata da palavra pela percepção visual, sendo que a criança ouvinte o fará pela percepção auditiva, apropriando-se do significado presente na combinação de sons própria de cada palavra. 


\section{Criança JA12: Palavras estáveis e a estabilidade das palavras}

$\mathrm{Na}$ entrevista de JA12 o ponto que se destacou foi o uso de palavras estáveis na sua produção escrita. JA12 usava a Libras para a sua comunicação e interação, conhecia e fazia uso dessa língua; conhecia as letras, escreveu-as da maneira cursiva, mas ainda estava em processo de aprendizagem do registro de suas formas. No início da entrevista, quando perguntado qual era o seu nome respondeu usando a datilologia e, em seguida, fez o seu sinal. Ao ser solicitado que escrevesse o seu nome, JA12 registrou-o seguido do sobrenome, usando a letra cursiva; e, antecedendo-o, escreveu a palavra "aluna", evidenciando que realizou esta ação como se estivesse cumprindo um ritual da sala de aula (TARTUCl; GÓES, 2014), algo que executa de forma repetida no seu cotidiano escolar.

Ao iniciar as atividades das produções escritas dos vocabulários, JA12 grafou o nome do pinguim com a palavra ANAINA e para registrar "leão" escreveu CANAINA. Para os demais animais - jacaré, girafa, polvo, macaco, urso e a menina Viviana - JA12 escreveu os seus respectivos nomes sem questionar, hesitando somente no início, registrando respectivamente BARA, CARCEZ, MARCIA, DIARCIA, CARCIA (as letras $C$ e $R$ não foram grafadas corretamente) e RCIAR (as letras $R$ no início e no fim da palavra não foram grafadas com clareza).

Observou-se que, para registrar os nomes dos animais, JA12 utilizou palavras que são estáveis para ela, como o seu próprio nome e o nome de sua colega de turma Márcia. Para Morais (2012, p. 136) "determinadas palavras se tornam estáveis para um aprendiz quando ele as reconhece de memória e pode tentar reproduzi-las, a partir do que memorizou sobre as letras que as constituem e sobre a ordem em que se encontram dispostas". Esse autor afirma que, além de seu próprio nome, os nomes de colegas, da professora, dos seus pais, entre outras podem se tornar estáveis para a criança diante da sua exposição frequente e do ato de registrar repetidamente, podendo ser um elemento importante para a reflexão das propriedades e mecanismos do sistema de escrita alfabético. Ainda nesta atividade, a pesquisadora, buscando investigar se a escrita se caracteriza como um recurso para a memória, perguntou à JA12 onde estavam escritos os respectivos nomes dos animais, constatando-se que ela utilizou algumas marcas da escrita para se lembrar de 
quais eram os nomes de determinados animais, mesmo que não estivessem grafados corretamente.

Quando realizou a produção textual do gênero carta, JA12 simulou que estava escrevendo, como se fosse uma ação imitativa; em seguida, copiou o nome da menina Viviana (com omissão de letra) na parte de baixo da folha de papel. Ao ser perguntado o que havia escrito, a colaboradora disse ser a resposta. Após algumas intervenções, escreveu sem interrupção.

O texto da carta da de JA12 tem um traçado diferente da forma como registrou o vocabulário; para escrever os nomes dos animais ela utilizou as letras e suas formas convencionais na forma cursiva, mas o texto foi escrito como rabiscos imitando as letras, que aparentavam grafar a palavra estável "Márcia" ou as suas partes. Entretanto, a sua produção não se caracterizou como um registro de caráter instrumental. Ao ser perguntado o que havia escrito, sinalizou literalmente "quantos porcos carta como entregou para menina".

Imagem 06: Texto produzido por JA12

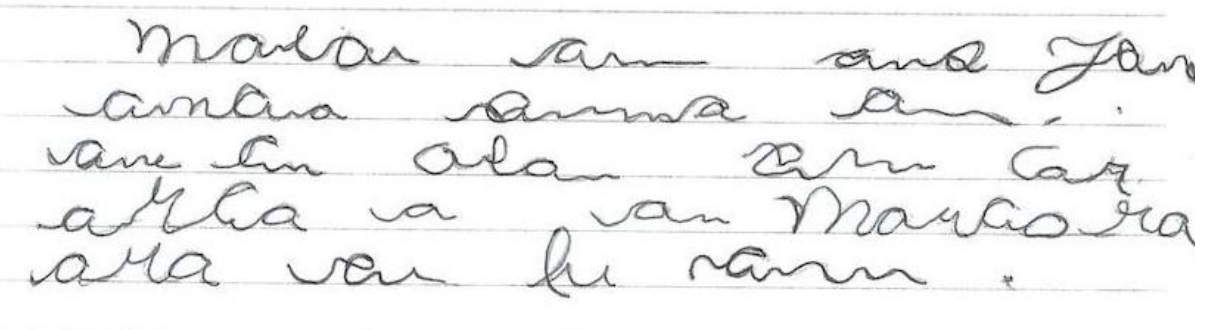

Fonte: Favoreto da Silva (2020)

Na esteira de Vygostsky (2001), ressalta-se que a formação do signo não é imutável e o seu desenvolvimento é individual, considerando que os signos se modificam conforme a criança se desenvolve e de acordo com as formas de funcionamento do pensamento; sendo que a modificação dos signos é resultante da capacidade cognitiva da criança de internalizar e mediar a sua experiência, gerando o conhecimento.

Verificou-se que JA12, na maioria das vezes, buscou realizar suas produções textuais de forma imitativa e repetitiva, seguindo os rituais da sala de aula. Entretanto, ainda citando Vygotsky (1984), é fundamental que a escrita seja algo de que a criança necessite, que tenha algum significado e que 
seja incorporada a uma atividade relevante para ela. Haja vista que o processo de apropriação da escrita envolve sistemas linguísticos abstratos e arbitrários, é fundamental a ação de um medidor (neste caso, o professor) que estabeleça essa relação, visando à aprendizagem dos alunos.

\section{Algumas considerações sobre a palavra dita}

Neste estudo, a Libras se evidenciou como a língua do pensamento dos colaboradores, pois por meio dela as crianças contavam coisas, perguntavam, formulavam hipóteses, brincavam, mostrando conhecer vários conceitos e fazendo uso deles no cotidiano. Gesueli (1998) também constatou em sua tese que a Libras é fundamental para desenvolvimento da criança surda, mas que não se deve ser simplista pensando que a língua de sinais resolverá todos os problemas encontrados em sala de aula.

Durante a realização das atividades de escrita verificou-se uma atividade mental de recorrência à memória que pode ser entendida como a fala egocêntrica; porém, considerando a idade dessas crianças, também é possível dizer que esta ocorrência pode ser o uso de um recurso cognitivo ao aprenderem outra língua, repetindo para si, palavras que estão sendo aprendidas. De acordo com Smolka (1993), no caso de crianças ouvintes, quando a criança fala, por meio da fala egocêntrica, o objetivo não é falar o texto, mas escrever o texto, desta forma a fala (oralidade), aparece como uma mediação, neste momento. Na atividade de escrita, que é discursiva e dialógica, a criança muda de lugar enquanto escreve, muda de voz enquanto fala, assumindo a posição de autor e, então, confundindo-se com o interlocutor na fala para si e enquanto leitor de seu texto. Dessa forma, Smolka (1993, p. 60) ressalta que "[...] nesse processo, as características da fala "egocêntrica" e da escrita se invertem: a fala para si é expandida, estendida e repetida, enquanto a escritura se apresenta contraída, condensada, abreviada."

$\mathrm{Na}$ análise das produções escritas das crianças, constatou-se que na fase inicial da escolarização não há distinção entre o processo de apropriação da língua portuguesa das crianças surdas e ouvintes, mesmo que essa não seja a língua utilizada pela criança surda como a língua de interação e de instrução. Nesta fase do desenvolvimento da escrita as crianças surdas adotaram como estratégias o uso: da escrita pictográfica; das letras que compõem os seus 
nomes com variações internas e combinações diferentes; de letras que conhecem, de forma aleatória; e de palavras que são estáveis para elas. Essas estratégias também podem ser encontradas em pesquisas realizadas sobre o desenvolvimento da escrita de crianças ouvintes nas obras de Luria (1988), Ferreiro e Teberosky, (1999), Morais (2012), dentre outros.

Esse processo se diferencia a partir do momento em que acontece o "ponto de virada" na compreensão do mecanismo do sistema de escrita. No caso da criança ouvinte, de acordo com Ferreiro e Teberosky (1999), esse momento se origina quando é realizada a correspondência da fala com a grafia , dissociando-a de seu significado e segmentando-a, no domínio de uma habilidade metalinguística; ou seja, a consciência fonológica é fundamental para o desenvolvimento da escrita na criança ouvinte. Para Luria (1988) e Vygotsky (1984), o ponto de virada evidencia-se no emprego da escrita instrumental, na sua utilização como apoio de funções intelectuais como requisito para o uso do sistema convencional, compreendendo que a criação de sinais escritos é representação dos símbolos falados das palavras, entendendo que se pode "desenhar" a fala. Esse momento em que a criança ouvinte começa a entender o mecanismo da escrita se diferencia do processo com a criança surda, diante do impedimento auditivo para fazer a correspondência da fala com a grafia.

Entretanto, em um segundo momento, verificou-se que as crianças surdas utilizaram pistas visuais para a escrita, como o uso de palavras que já conhecem, que contêm letras em comum com o objeto a ser denotado e/ou o registro de pseudo-palavras (PEREIRA, 2015). Neste contexto, para o entendimento do mecanismo e da lógica do sistema de escrita alfabética pelas crianças surdas, problematiza-se como se efetiva "o ponto de virada" de sua apropriação da escrita, tendo em vista que acontece de forma distinta ao da criança ouvinte. Uma das hipóteses evidenciadas é que as crianças surdas começam a perceber as pistas visuais da grafia da palavra, fazem cópias das palavras e tentativas de escrita, por meio atividades mentais que podem estar relacionadas à consciência visual (OLIVEIRA, 2009). O conceito de consciência visual pode ser entendido como um mecanismo que visa à: "[...] representação visual do objeto - a imagem; abstração do objeto como unidade constituídas de partes, resultando na representação simbólica do objeto, através da língua de sinais e posterior escrita alfabética" (OLIVEIRA, 2009, p. 196). 
Nessa perspectiva, o letramento visual se apresenta como um fator de relevância no processo de escolarização das pessoas surdas, ressaltam Gesueli e Moura (2006), havendo a necessidade da organização do trabalho envolvendo o letramento visual para uma maior compreensão das informações e experiências pelos sujeitos, proporcionado as habilidades para a leitura de imagens e um maior refinamento dessa leitura, tendo em vista que não é uma capacidade inata do homem (SANTAELLA, 2012; DONDIS, 2015). Diante do exposto, a mediação do professor se torna fundamental, pois diferentemente da aquisição da língua de sinais, que acontece naturalmente entre os pares surdos, a escrita é uma função que se realiza pela forma do ensino sistemático e, culturalmente, por mediação, de acordo com Vygotsky (1984) e Luria (1988).

Neste contexto, considera-se importante conceber que a alfabetização e letramento das crianças surdas se constituam em bases diferentes daquelas utilizadas no ensino da língua escrita para crianças ouvintes. Quando não se adota essa perspectiva insere-se uma distorção nas comparações usualmente feitas entre os resultados das produções de surdos e ouvintes. Deixa-se de levar em conta que os surdos não podem compreender o sistema de escrita com o uso de algo que é particular aos ouvintes: a consciência fonológica.

Tendo em vista que as crianças surdas aprendem a partir de outras experiências que são fundamentadas em um pressuposto bilíngue e visual, e não por meio do uso da consciência fonológica, aponta-se para a alfabetização e letramento bilíngue como uma hipótese para contribuir com o "ponto de virada" da criança surda. A alfabetização e letramento bilíngue podem ser compostos por um conjunto de práticas pedagógicas que envolvem as especificidades da Libras e da língua portuguesa no processo de apropriação da escrita, contendo elementos como: a escrita de sinais, a escrita diferida e a escrita bilíngue. Estes elementos podem contribuir com a aquisição de novos mecanismos para a abstração na apropriação da língua escrita, com a produção de significados nas narrativas e contemplando especificidades que são comuns em textos realizados em português por pessoas surdas, em uma perspectiva de segunda língua.

Evidenciou-se, também, a necessidade do trabalho efetivo com gêneros textuais para que a criança perceba que os textos são instrumentos que ela pode usar para se comunicar com as pessoas e que não são apenas um amontoado de letras, pois no uso de práticas sociais letradas, na esteira de Marcuschi (2008), os gêneros podem ser utilizados enquanto possibilidades de 
comunicação verbal e o seu uso pedagógico diz respeito ao trato dos gêneros enquanto o trato da língua em seu cotidiano nas mais diversas formas. $E$, diante da importância que a visualidade tem no processo de desenvolvimento da escrita dessas crianças, em sintonia com Kress e van Leeuwen (2001) no que diz respeito aos múltiplos gêneros discursivos que circulam na sociedade, que essas práticas não sejam somente pautadas na fala e na escrita, mas que sejam inseridas outras semioses em uma perspectiva multimodal, assim como apontado por Gesueli e Moura (2006), Figueiredo e Guarinello (2013), Lebedeff (2017) e Peluso (2018), rompendo com o reducionismo da linguagem fundada na oralidade.

Assim, ao finalizar este trabalho, há a pretensão de compartilhar o que foi escrito, de provocar deslocamentos e novas experiências, buscando contribuir com as pesquisas na área da educação de surdos; pois, " se alguma coisa nos anima a escrever é a possibilidade de que esse ato de escritura, essa experiência em palavras, nos permita liberar-nos de certas verdades, de modo a deixarmos de ser o que somos para ser outra coisa, diferente do que vimos sendo" (LARROSA; KOHAN, 2015, s/p).

\section{Referências}

AZENHA, M. da G. Imagens e Letras: Ferreiro e Luria duas teorias psicogenéticas. São Paulo: Ática, 1995.

DONDIS, D. A. Sintaxe da linguagem visual. Tradução Jefferson Luiz Camargo. 3a ed. São Paulo: Martins Fontes, 2015.

FAVORETO DA SILVA, R. A. Experiências de crianças surdas com a palavra escrita. 2020. 412 f. Tese (Doutorado em Educação) - Programa de PósGraduação em Educação, Faculdade de Educação, Universidade de São Paulo, São Paulo, 2020.

FERREIRO, E.; TEBEROSKY, A. Psicogênese da língua escrita. Porto Alegre: Artmed, 1999.

FIGUEIREDO, L. C.; GUARINELLO, A. C. Literatura infantil e a multimodalidade no contexto de surdez: uma proposta de atuação. Revista Educação Especial, 
vol. 26, n. 45, jan./abr., pp. 175-192, Santa Maria: Universidade Federal de Santa Maria, 2013.

GESUELI, Z. M. A criança surda e o conhecimento construído na interlocução em língua de sinais. 1998. Tese (Doutorado em Educação) - Programa de PósGraduação em Educação, Universidade de Campinas, Campinas, SP, 1998.

GESUELI, Z. M.; MOURA, L. de. Letramento e Surdez: a visualização das palavras. ETD - Educação Temática Digital, Campinas, v.7, n.2, p.110-122, jun. 2006.

GÓES, M.C.R.; TARTUCI, D. Alunos surdos na escola regular: as experiências de letramento e os rituais de sala de aula. In: LODI, A.C.B.; HARRISON, K.M.P.; CAMPOS, S.R.L.; TESKE, O. (Org.) Letramento e minorias. 7. ed. - Porto Alegre: Editora Mediação, 2014, p.111-120.

KARNOPP, L. B.; LOPES, Maura C. Os surdos aprendem melhor nas escolas para surdos ou nas escolas regulares?. Pátio: Ensino Fundamental, Porto Alegre, p. 42-45, fev. 2014.

KRAMER, S. Autoria e autorização: questões éticas na pesquisa com crianças. Cadernos de Pesquisa, São Paulo, n. 116, jul. 2002, p. 41-59.

KRESS, G.; van LEEUWEN, T. Multimodal discourse: The modes and media of contemporary communication. London, New York: Arnold; Oxford University Press, 2001.

LAROSSA, J.; KOHAN, W. Apresentação da coleção. In: LAROSSA, J. Tremores: escritos sobre experiência. Tradução Cristina Antunes, João Wanderley Geraldi. 1. ed. Belo Horizonte: Autêntica Editora, 2015.

LEBEDEFF, T. B. O povo do olho: uma discussão sobre a experiência visual e surdez. In: LEBEDEFF, T. B. (Org.). Letramento visual e surdez. Rio de Janeiro: Wak Editora, 2017, p. 226-251. 
LIMA, M. F. de; ALVES, E. de O.; STUMPF, M. R. Escrita de Sinais: uma proposta para o letramento de surdos em L1. In: Revista Prática Docente, v. 3, n. 1, p. 140-157, jan/jun, 2018.

LURIA, A. R. O desenvolvimento da escrita na criança. In: VIGOTSKII, L. S.; LURIA, A. R.; LEONTIEV, A. N. Linguagem, desenvolvimento e aprendizagem. Tradução Maria da Penha Villalobos. São Paulo: Ícone Editora: Editora da Universidade de São Paulo, 1988, p. 143-189.

MACHADO, E. de L. Psicogênese da leitura e da escrita na criança surda. Tese (Doutorado em Psicologia da Educação). Pontifícia Universidade Católica de São Paulo, São Paulo, 2000.

MARCUSCHI, L. A. Produção textual, análise de gêneros e compreensão. São Paulo: Parábola Editorial, 2008.

MORAIS, A. G de. Sistema de Escrita Alfabética. São Paulo: Editora Melhoramentos, 2012.

MÜLLER, J. I; KARNOPP, L. B. Educação escolar bilíngue de surdos. 37ạ Reunião Nacional da ANPEd - 04 a 08 de outubro de 2015, UFSC - Florianópolis, 2015. Disponível em:

http://37reuniao.anped.org.br/wp-content/uploads/2015/02/Trabalho-GT154077.pdf. Acesso em: 20 jun. 2019.

OLIVEIRA, M. K. de. Pensar a educação: contribuições de Vygotsky. In: CASTORINA, J. A.; FERREIRO, E.; LERNER, D.; OLIVEIRA, M. K. de. PiagetVygostky: novas contribuições para o debate. Tradução Claudia Schilling. 6. ed. São Paulo: Editora Ática, 2000.

OLIVEIRA, T. C. B. C. de. A escrita do aluno surdo: interface entre a Libras e a Língua Portuguesa. 2009. Tese (Doutorado em Educação), Universidade Federal da Bahia, Faculdade de Educação, Salvador, BA, 2009. 
PELUSO, L. Los sordos, sus lenguas y su textualidad diferida. Traslaciones Revista Latinoamericana de lectura y escritura, Mendoza, v. 5, n. 9, p. 40-61, jul. 2018.

PEREIRA, M. C. da C.; ROCCO, G. C. Aquisição da escrita por crianças surdas início do processo. In: Letrônica. Porto Alegre, v. 2, n. 1, p. 138 - 149, jul. 2009.

PEREIRA, M. C. da C. Reflexões sobre a aquisição da escrita da língua portuguesa por criança surda usuária da Língua Brasileira de Sinais. In: Revista Espaço, INES, Rio de Janeiro, n. 43, jan./jun. 2015.

SANTAELLA, L. Leitura de imagens. São Paulo: Editora Melhoramentos, 2012.

SILVA, T. dos S. A. da. A aquisição da escrita pela criança surda desde a Educação Infantil. 2008. Tese (Doutorado em Educação) - Programa de PósGraduação em Educação, Universidade Federal do Paraná, Curitiba, PR, 2008.

SMOLKA, A. L. B. A dinâmica discursiva no ato de escrever: relações oralidadeescritura. In: SMOLKA, A. L. B.; GOES, M. C. R. (Org.). A linguagem e o outro no espaço escolar: Vygotsky e a construção do conhecimento. Campinas: Papirus, 1993. p. 33-62.

SOARES, M. Alfabetização: a questão dos métodos. São Paulo: Contexto, 2016.

STUMPF, M. R. Sistema signwriting: por uma escrita funcional para o surdo. In: THOMA, A. da S.; LOPES, M. C. (Orgs.) A invenção da surdez: cultura, alteridade, identidade e diferença no campo da educação. Santa Cruz do Sul: EDUNISC, 2004, p. 143-159.

VYGOTSKY, L. S. A formação social da mente. Tradução José Cipolla Neto, Luis Silveira Menna Barreto e Solange Castro Afeche. São Paulo: Martins Fontes, 1984.

VYGOTSKY, L. S. A construção do pensamento e da linguagem. Tradução Paulo Bezerra. São Paulo: Martins Fontes, 2001. 